\title{
Unacylated ghrelin modulates circulating angiogenic cell number in insulin-resistant states
}

\author{
Behiye Özcan ${ }^{*}$, Pieter J. M. Leenen², Patric J. D. Delhanty ${ }^{1}$, Lucy Y. Baldéon-Rojas², Sebastian J. Neggers ${ }^{1}$ \\ and Aart Jan van der Lely ${ }^{1}$
}

\begin{abstract}
Background: Type 2 diabetes (T2D) is associated with reduced numbers and impaired function of circulating angiogenic cells (CAC) which contributes to the progression of atherosclerosis and microvascular disease. Previous studies suggest that short-term infusion of unacylated ghrelin (UAG) normalizes CAC number in patients with T2D. To determine dose-dependent effects of short-term infusion of UAG in T2D patients using a cross-over model, and of long-term infusion of UAG in obese mice, on differentiation of monocyte progenitors into CAC.

Methods: Eight overweight T2D patients were infused overnight with 3 and $10 \mu \mathrm{g} / \mathrm{kg} / \mathrm{h}$ of UAG in a double-blind, placebo-controlled cross-over study. To assess the effects of long-term UAG treatment, obese mice were infused with UAG for 4 weeks. Monocyte progenitors were assessed for their ability to differentiate into CAC in vitro.

Results: In T2D patients, UAG treatment caused a reduction in differentiation of CAC, dependent on UAG dose and differentiation method. However, mice treated with UAG showed a significant increase in differentiation of bone marrow progenitors into CAC.
\end{abstract}

Conclusion: UAG causes a minor suppressive effect on CAC development after short-term treatment in humans, but experiments in mice suggest that long-term treatment has beneficial effects on CAC formation.

The Netherlands Trial Register: $\mathrm{TC}=2487$

Keywords: Diabetes, Circulating angiogenic cell, Unacylated ghrelin, Insulin resistant, Obese

\section{Background}

Ghrelin is a 28 amino acid peptide that is secreted predominantly by X/A-like cells in the stomach. It circulates in two different forms: acylated ghrelin (AG) and unacylated ghrelin (UAG; also named des-acyl ghrelin) $[1,2]$. AG is acylated with octanoic acid at serine 3 by ghrelin $O$-acyl transferase (GOAT), whereas UAG is not [3]. Ghrelin was discovered in 1999 as the endogenous ligand of the orphan growth hormone secretagogue receptor (GHSR1a) that had previously been identified as the receptor mediating the pharmacological effects of

\footnotetext{
*Correspondence: b.ozcan@erasmusmc.nl

${ }^{1}$ Department of Internal Medicine, Erasmus MC, Rotterdam, The Netherlands

Full list of author information is available at the end of the article
}

a new therapeutic class of compounds, the growth hormone secretagogues [4]. Ghrelin was initially characterized for its property of inducing growth hormone (GH) secretion, a function mediated by GHSR1a [4].

Today, however the ghrelin system is known to exert numerous biological effects on the secretion of several pituitary hormones, on gastric acid secretion and gutmotility, on exocrine and endocrine pancreatic function and glucose metabolism, appetite stimulation and the cardio-vascular and immune system [2, 5]. Since UAG only activates GHSR1a at supra-physiological concentrations [6], and has no physiological effect on GH secretion [7], it has long been considered not to have a physiological role.

Clinical evidence suggests that UAG prevents the diabetogenic effects of AG in healthy volunteers and in 
GH-deficient patients [2, 8], primarily by improving insulin-sensitivity. Importantly, we have recently shown that UAG treatment rapidly improves insulin sensitivity in type 2 diabetic subjects [9]. How it can exert effects in several disparate (patho)physiological systems and conditions remains to be answered. In metabolically active tissues of GHSR-deficient mice, UAG rapidly modulates lipogenic and insulin signaling pathway gene expression [10], indicating a GHSR-independent mechanism of action, although a receptor for UAG remains to be discovered. Recently, we have also shown that UAG infusion in obese mice causes insulin-sensitizing effects [11].

Vascular complications are the major source of morbidity and mortality among patients with diabetes [12]. Diabetes mellitus is associated with a 2- to 4-fold increase in rates of macrovascular disease [13]. This is due to macrophage accumulation in the vascular wall and subsequent secretion of multiple proinflammatory growth factors and cytokines, a very important step in the pathological mechanism causing atherosclerosis [14].

Monocytes and monocyte-derived cells are important in detecting and repairing vascular damage, in particular by producing proangiogenic factors which promote neovascularization and endothelial repair. These vesselprotective cells have previously been indicated as myeloid EPC $[15,16]$, but are now more accurately termed proangiogenic cells or circulating angiogenic cells (CAC). We will use the latter term throughout this study. CAC are involved in restoration of vascular homeostasis in diabetics. Monocyte differentiation and function in patients with diabetes is altered by metabolic conditions, resulting in the decreased ability of these cells to participate in vascular maintenance and repair [17-19]. Data from recent experiments on CAC suggest that UAG may beneficially impact the vascular remodeling process which is known to be impaired in type 2 diabetes patients [20,21].

The aims of the current study are to extend the findings of Togliatto et al. by examining the dose and timedependent effects of in vivo UAG treatment on in vitro differentiation of isolated monocytes into CAC using different protocols, and into their presumed non-protective counterparts, macrophages. To do this, we first examined the effects of a short-term, i.e. overnight infusion of UAG at 3 and $10 \mu \mathrm{g} / \mathrm{kg} / \mathrm{h}$ in T2D patients on differentiation of peripheral blood monocytes into CAC and macrophages. Since long-term UAG treatment of humans is not ethically feasible, we infused lean and obese mice with vehicle or UAG at $10 \mu \mathrm{g} / \mathrm{kg} / \mathrm{h}$ for 4 weeks and examined their effect on differentiation of CAC from bone marrow monocyte progenitors.

\section{Methods}

\section{Study drug}

UAG was obtained from Bachem AG, Hauptstrasse 144, Bubendorf $\mathrm{CH}-4416$, Switzerland. UAG was delivered as lyophilized powder (vials containing $5 \mathrm{mg}$ of drug) and stored as indicated by the manufacturer. The same peptide preparation was used for both animal and human experiments.

\section{Human peripheral blood mononuclear cell cultures Study design}

This study is a single-center, investigator-initiated, double blind and placebo-controlled randomized study [9]. The study was conducted in Erasmus University Medical Center Rotterdam after approval by the local IRB. All subjects gave their written informed consent before enrollment. The study included three overnight hospital admissions. During these three admissions, all subjects received either placebo, or UAG at 3 or $10 \mu \mathrm{g} / \mathrm{kg} / \mathrm{h}$ in randomized order as a continuous infusion via an indwelling catheter as described below. A washout period of at least 1 week was used between the different treatment periods. Placebo or UAG was continuously infused for $15 \mathrm{~h}$ from 22:00 $h$ until 13:00 $h$ the next day. At 8:00-8:15 $h$ the following morning, a standard breakfast meal (SBM) was served: $714 \mathrm{kcal}$ (46\% fat, $17 \%$ proteins, $37 \%$ carbohydrates). Before the start of each infusion period a continuous glucose monitor (iPro2, Medtronic trading, The Netherlands) was inserted to measure the subcutaneous interstitial blood glucose [22-25].

Blood samples for isolating monocyte progenitors were collected before (16:00) and after (the next day at 14:00) the infusion period.

\section{Subjects}

Eight subjects were enrolled ( 2 females -6 males; mean age 53 years (range 31-65 years). Mean body mass index (BMI) was $31.5 \mathrm{~kg} / \mathrm{m}^{2}$, range $26-40.1 \mathrm{~kg} / \mathrm{m}^{2}$. All subjects were diagnosed with type 2 diabetes for at least 3 months prior to enrollment. Mean glycosylated hemoglobin levels (HbA1c) were 49 (41-55) mmol/mol [6.6 (5.9-7.2)\%]. Exclusion criteria were a history or presence of longterm type 2 diabetes complications; clinically significant abnormalities in laboratory evaluation at screening, and the use of systemic corticosteroids within 60 days prior to screening.

Four of eight patients were medicated with statins and two with antihypertensive drugs. All patients were being treated with metformin that was stopped 1 day prior to the start of each treatment period. 


\section{Peripheral blood mononuclear cell cultures}

Peripheral blood mononuclear cells (PBMC) were obtained by density gradient centrifugation (Ficoll-Paque PLUS, GE Healthcare 17-1440-03) of $50 \mathrm{ml}$ of peripheral blood collected in sodium heparin tubes. CAC, also called early endothelial progenitor cells (EPC) or myeloid EPC, were cultured according to two different protocols as described by Murohara et al. and by Asahara et al. $[26,27]$. These cultures are referred to as Toyo-CAC and EBM-CAC, respectively.

In both cultures, PBMC were plated in triplicate at a density of $2 \times 10^{6} \mathrm{cells} / \mathrm{ml} /$ well in 24 -well plates (Nunc) coated with $10 \mu \mathrm{g} / \mathrm{ml}$ of human fibronectin (Sigma). For Toyo-CAC, cells were cultured in M199 medium supplemented with $10 \%$ FCS, $0.05 \mathrm{mg} / \mathrm{ml}$ bovine pituitary extract (Invitrogen), 10,000 U penicil$\mathrm{lin} / \mathrm{ml}, 10,000 \mathrm{U}$ streptomycin/ml (Lonza DE17-602E), and 10 units/ml heparin (Leo Pharma BV) at $37{ }^{\circ} \mathrm{C}$ and $5 \% \mathrm{CO}_{2}$. For EBM-CAC, cells were cultured in EBM-2 + EGM-2 (Lonza 3156; 4176) at $37{ }^{\circ} \mathrm{C}$ and $5 \%$ $\mathrm{CO}_{2}$. After 7 days of culture, Toyo-CAC and EBM-CAC cultures were washed profusely with PBS to retain only the adherent spindle-shaped cells. Cells were then fixed with paraformaldehyde (PFA, 4\%) for $15 \mathrm{~m}$ at room temperature.

To generate human macrophages from monocytes under similar conditions, total PBMC were cultured in triplicate at a density of $1 \times 10^{6}$ cells/well at $37{ }^{\circ} \mathrm{C}$ and $5 \% \mathrm{CO}_{2}$ in 24-well plates for 7 days in RPMI ( $25 \mathrm{mM}$ Hepes, with Ultraglutamin-1) supplemented with human $A B$ serum (Lonza 14-490E), 10,000 U penicillin/ml, 10,000 U streptomycin/ml (Lonza DE17-602E), and 10\% M-CSF-containing conditioned medium from Ladmac cells [28]. Fresh growth factor $(100 \mu \mathrm{l})$ was added to each well on days 3 and 6 . At day 7, plates were centrifuged at $1200 \mathrm{rpm}$ for 3 min at $4{ }^{\circ} \mathrm{C}$ and cells were fixed with PFA (4\%).

The quantification of cultures was performed fluorometrically on the basis of DNA content as assessed by propidum iodide staining [29]. Briefly, wells were incubated with $20 \mu \mathrm{l}$ propidium iodide $(4 \mu \mathrm{l} / \mathrm{ml}$; Sigma). After $10 \mathrm{~min}$ the fluorescence intensity was measured using a FLUOstar Optima plate reader (BMG Labtech, Ortenberg, Germany). Interpolation on a standard curve of PBMC was used to determine absolute cell numbers.

\section{Differentiation of CAC from bone marrow of lean and obese mice infused with UAG}

C57BL/6 mice (10 week, male; Charles River Laboratories, Maastricht, The Netherlands) were maintained at $12: 12 \mathrm{~h}$ light: dark, $21{ }^{\circ} \mathrm{C}$, with free access to food and water. Normal (ND) and high fat (HFD) diets were from special diets services (Tecnilab-BMI, Someren, The Netherlands; product code 801722, 9\% kcal from fat,
69\% from carbohydrate, $22 \%$ from protein) and ABDiets (Woerden, The Netherlands; $41 \% \mathrm{kcal}$ from fat, $40 \% \mathrm{kcal}$ from carbohydrate, $19 \% \mathrm{kcal}$ from protein), respectively. Animal experiments were performed with the approval of the Animal Ethics Committee at Erasmus MC (approval code: EMC2050). Mice were implanted with subcutaneous Alzet 1004 mini-osmotic pumps (Durect Corp., Cupertino, CA, USA) containing saline or UAG. UAG was infused at $10 \mu \mathrm{g} / \mathrm{kg} / \mathrm{h}$. Mice were split into two groups 2 weeks after pump implantation $(\mathrm{n}=3$ for each of the 4 experimental groups), either continuing to receive the ND or given free access to the HFD, as previously described [11]. At the end of the 4 week infusion period, bone marrow was collected from the femurs and tibiae, and culture of CAC/endothelial progenitor cells was performed as previously described [30].

Weight and food intake were recorded 1 week before and weekly during the period of treatment. Data on weight, fat mass, glucose and insulin levels in these mice are described in Delhanty et al. [11].

\section{Results}

Assessment of dose-dependent effects of UAG in humans Baseline values of generated EBM-CAC, Toyo-CAC and macrophages are shown in Fig. 1, representing the retrieval of these cell types from cultures of PBMC obtained before the initiation of treatment. In both types of CAC cultures as well as in the macrophage cultures, a significant degree of variation was observed with respect to the absolute number of $\mathrm{CAC}$ and macrophages retrieved. This variation occurred not only between different patients, but also among different samples from the same patients obtained at different visits. Baseline culture results from some patients were relatively consistent, while results from others showed high degrees of variation, suggesting a strong influence of variable patient conditions upon admission. Furthermore, cells from some patients showed a virtually complete inability to generate either type of CAC and/or macrophages. For instance, cells from patient \#7 generated virtually no EBM-CAC and macrophages, while Toyo-CAC could be readily measured. Another patient \#2 generated virtually no Toyo-CAC or macrophages, but EBM-CAC could be shown, though at variable levels. These baseline findings also indicate that both types of CAC cultures and macrophage cultures measure essentially distinct parameters. This is confirmed by a correlation analysis of the culture yields before and after treatment (Figs. 2, 3). This shows that a significant correlation exists only between the quantity of EBM-CAC and macrophages at baseline (Fig. 2b), but this correlation is lost after treatment with UAG (Fig. 3b). 
EBM-CAC

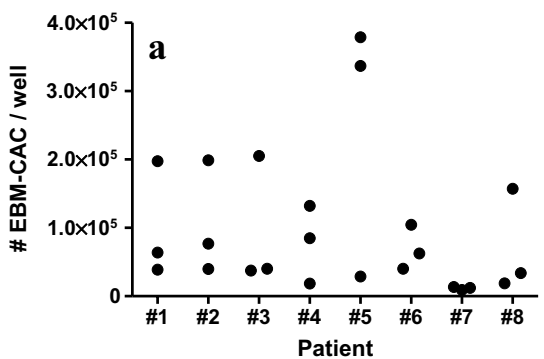

TOYO-CAC

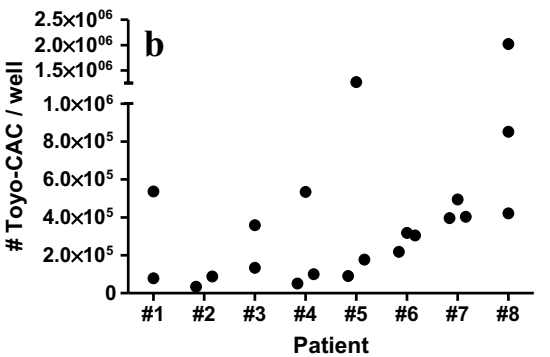

macrophages

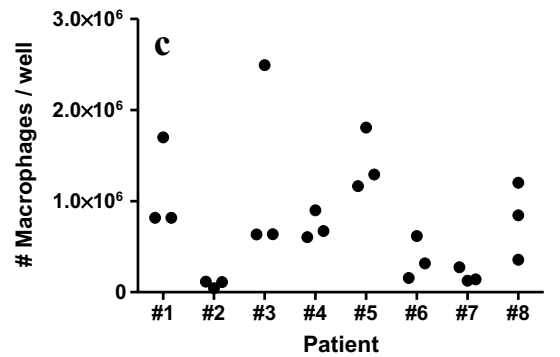

Fig. 1 Baseline values for the generation of Toyo-CAC, EBM-CAC, and macrophages. PBMC were isolated from patients at admission, before treatment, and cultured under different conditions to generate EBM-CAC (a), Toyo-CAC (b), or macrophages (c). Each of the three data-points per patient represents the average of three replicate wells
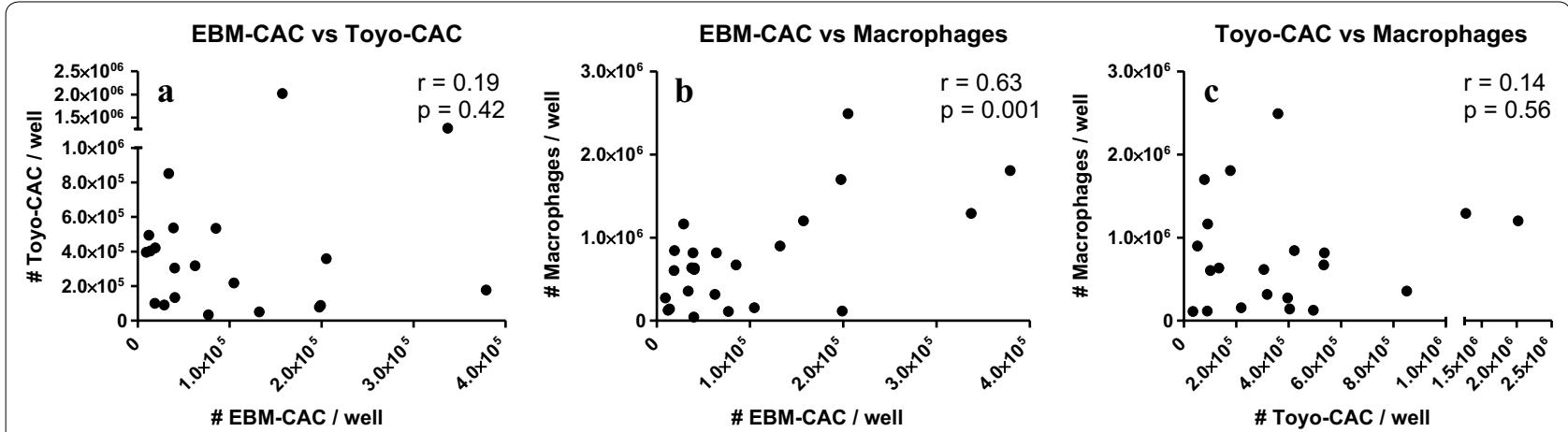

Fig. 2 Correlation between EBM-CAC, Toyo-CAC and macrophage baseline culture yields. Outcomes of EBM-CAC, Toyo-CAC and macrophage cultures were correlated. A significant correlation was observed only between EBM-CAC and macrophage cultures (b), but not between the two types of CAC cultures (a), or the Toyo-CAC and macrophages (c)

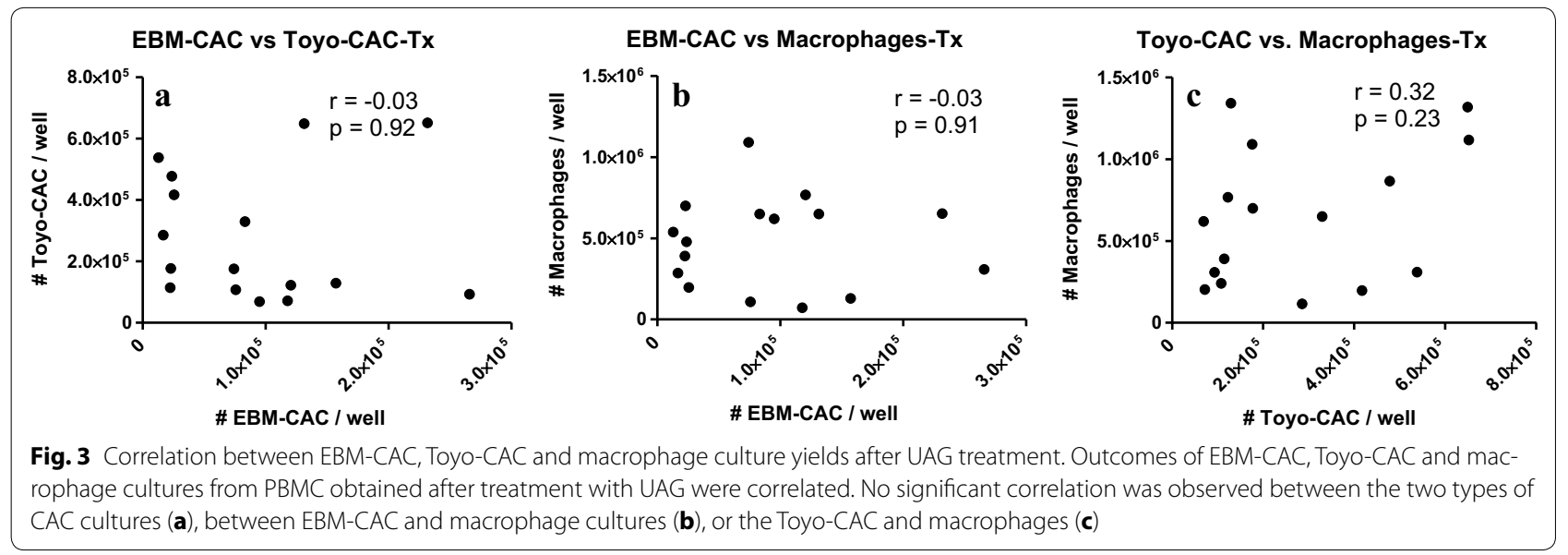

The effect of treatment of patients with 3 or $10 \mu \mathrm{g}$ UAG $/ \mathrm{kg} / \mathrm{h}$ on CAC and macrophage numbers is shown graphically for each patient in Fig. 4. Table 1 indicates the quantification of these changes, expressed as mean cell count normalized to the mean pre-treatment value. Clearly, the treatment effects were very diverse, and major differences between and among patients were observed. Even the direction of change differed, although for both types of CAC cultures high pre-treatment measurements tended to decrease upon treatment, 

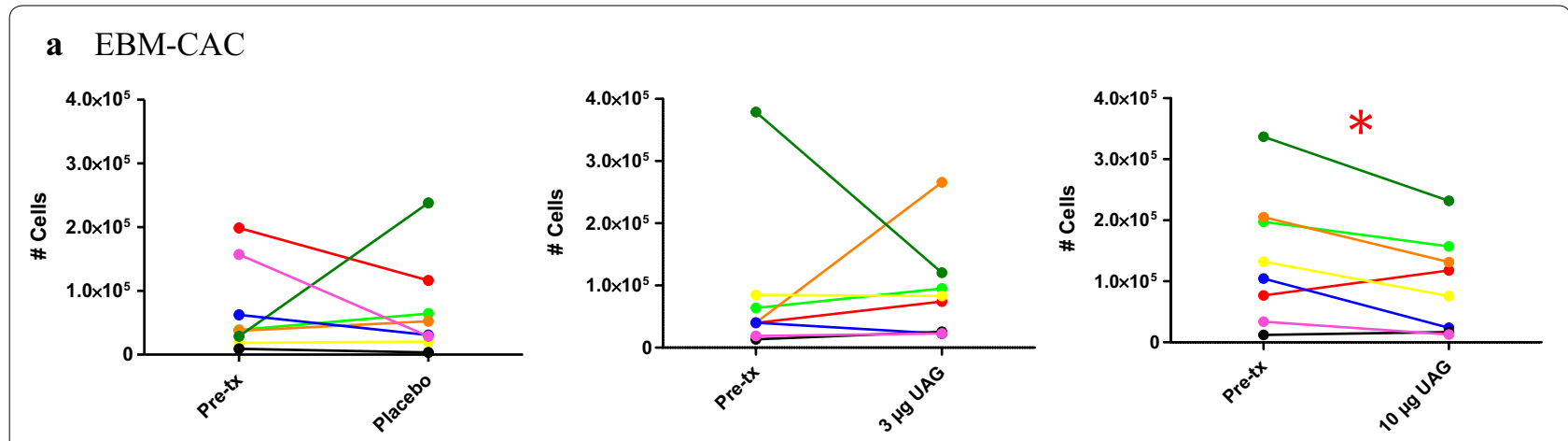

\section{b Toyo-CAC}
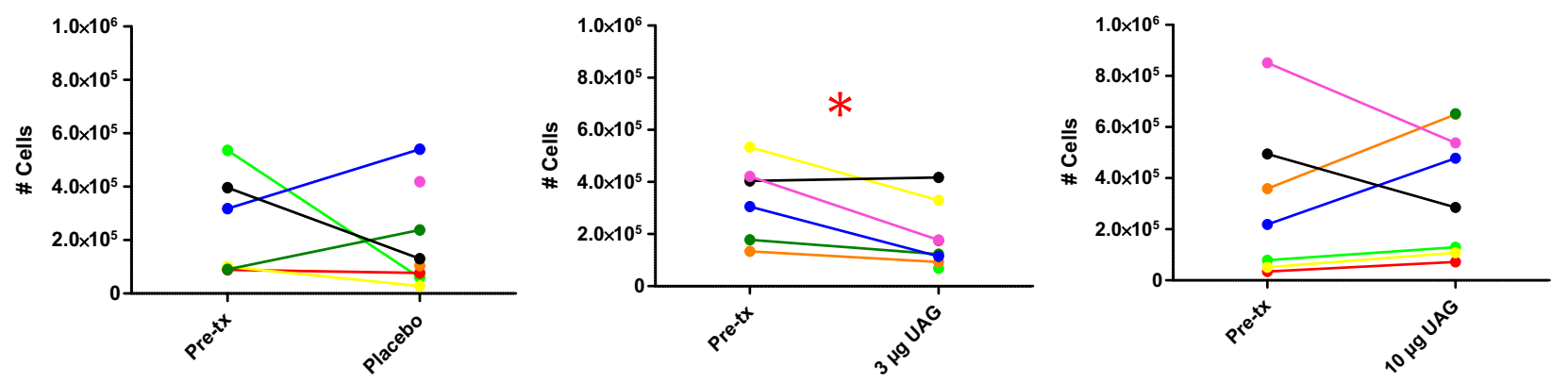

c Macrophages
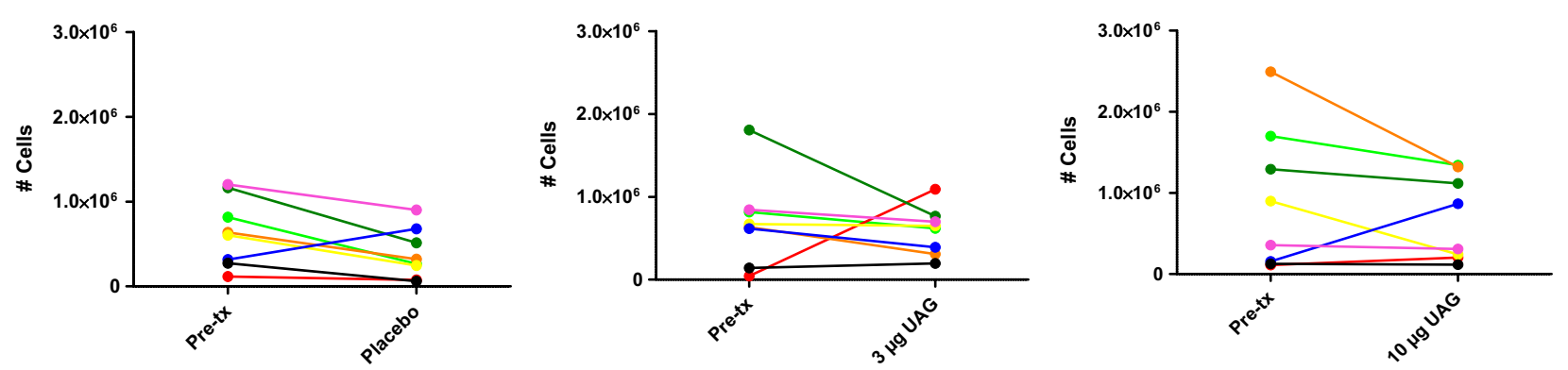

Fig. 4 Treatment-related changes in the quantity of obtained EBM-CAC, Toyo-CAC and macrophages. For each patient, the yields of EBM-CAC (a), Toyo-CAC (b) and macrophages (c) derived from PBMC isolated from pre- and post-treatment samples are shown. Each data point represents the average of three individual wells. Quantitative analysis of these data is shown in Table 1

while low pre-treatment values increased (Fig. 4a, b). Only in two conditions were statistically significant differences observed between pre- and post-treatment samples: treatment with $10 \mu \mathrm{g} / \mathrm{kg} / \mathrm{h}$ UAG reduced EBMCAC to $70 \%(\mathrm{p}=0.045)$, while treatment with $3 \mu \mathrm{g} / \mathrm{kg} / \mathrm{h}$ UAG caused reduction of Toyo-CAC to $60 \%(\mathrm{p}=0.038)$ (Table 1). Enigmatically, however, in both cases treatment with the lower or higher concentration, respectively, did not show a similar trend.

For the macrophage cultures, the yield of cells posttreatment tended to decrease in all cases including placebo treatment (Fig. 4c), although single measurements showing increased macrophage yield prevented attainment of statistical significance.

\section{Assessment of long-term treatment with UAG in mice}

Since short-term treatment of humans with UAG had relatively inconsistent effects, we wanted to determine if longer-term treatment might change this outcome. However, for ethical reasons, long-term treatment of humans is not yet possible. Therefore we used a model of diet-induced obesity in mice. The HFD caused a significant increase in fat mass which was prevented by infusion of UAG, as described in our previous publication [11]. In that study, we also found that UAG infusion prevented the glucose intolerance and insulin resistance that accompanied this increase in fat mass. Testing the effect of 4 weeks of UAG infusion on the differentiation of CAC from bone marrow progenitors showed that infusion of 
Table 1 Treatment-related changes in the yield of CAC and macrophages

\begin{tabular}{llll}
\hline Culture & Treatment & $\begin{array}{l}\text { Normalized mean cell } \\
\text { count post-tx }\end{array}$ & $\boldsymbol{p}$ value $^{\mathbf{b}}$ \\
\hline EBM-CAC & Placebo & $1.1 \pm 1.2$ & 0.219 \\
& $3 \mu \mathrm{g} / \mathrm{kg} / \mathrm{h}$ & $1.0 \pm 1.0$ & 0.938 \\
& $10 \mu \mathrm{g} / \mathrm{kg} / \mathrm{h}$ & $0.7 \pm 0.6$ & 0.045 \\
Toyo-CAC & Placebo & $0.8 \pm 0.7$ & 0.507 \\
& $3 \mu \mathrm{g} / \mathrm{kg} / \mathrm{h}$ & $0.6 \pm 0.4$ & 0.038 \\
& $10 \mu \mathrm{g} / \mathrm{kg} / \mathrm{h}$ & $1.2 \pm 0.8$ & 0.780 \\
macrophages & Placebo & $0.6 \pm 0.5$ & 0.053 \\
& $3 \mu \mathrm{g} / \mathrm{kg} / \mathrm{h}$ & $0.9 \pm 0.4$ & 0.617 \\
& $10 \mu \mathrm{g} / \mathrm{kg} / \mathrm{h}$ & $1.0 \pm 0.8$ & 0.097 \\
\hline
\end{tabular}

For each patient, the baseline values of that specific visit were compared with culture yields after treatment

a The mean obtained cell number of pre-tx samples was set at 1 ; mean post-tx number is expressed relative to this $\pm S D$

b Significance was determined by paired $t$ test

UAG in both ND-fed lean mice as well as mice given a short-term HFD caused a consistent, significant increase in recovery of CAC from bone marrow cultures (Fig. 5).

\section{Discussion}

Previous studies have indicated that T2D is associated with reduced numbers of monocyte-derived CAC [17-19]. Reduced numbers and impaired function of these monocytes in diabetes increased atherosclerosis. Endothelial injury is thought to represent an important step in the initiation and progression of atherosclerotic vascular disease [31]. As mentioned earlier, UAG may have beneficial effects on the vascular remodeling process in T2D patients [20,21]. Early CAC play a very important role in this process. To further investigate the effect of UAG treatment on CAC, and compare this to macrophage-forming potential, we performed two in vivo studies: a short-term study to assess dosedependency of UAG effects in T2D patients; and a study to investigate the effects of long-term UAG treatment in mice with decreased insulin sensitivity induced by dietinduced obesity. In humans, we studied the effects of a continuous overnight infusion of UAG or placebo in eight overweight mild type 2 diabetics. We found that short-term infusion of UAG had significant suppressive effects on CAC number at different doses, but this was dependent on differentiation procedure. Our findings are not consistent with those of Togliatto who found that systemic overnight administration of UAG at $3 \mu \mathrm{g} / \mathrm{kg} / \mathrm{h}$ (our low dose) prevented diabetes-induced EPC decrease, and increased endothelial progenitor cell mobilization in individuals with T2D [20]. It is currently unknown how UAG interferes with the differentiation of the cells. There

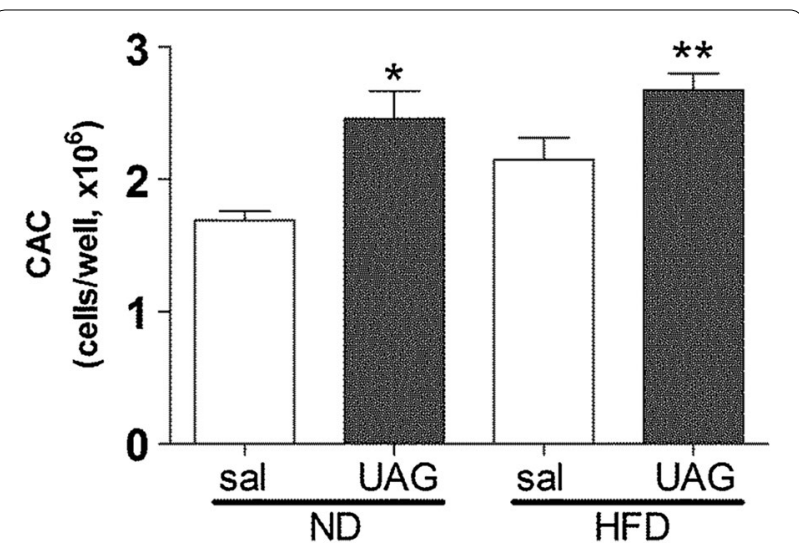

Fig. 5 Effect of UAG infusion endothelial progenitor cell recovery from murine bone marrow cell cultures. Mice infused for 4 weeks with UAG fed either a normal or high fat diet during the last 2 weeks of treatment. Bone marrow was then isolated and cultured to generate endothelial progenitor cells (aka. CAC). The data represents the average recovery of cells in three replicate wells of bone marrow cells from three different mice. ${ }^{*} p<0.05 ;{ }^{* *} p<0.01$ versus ND saline group; ANOVA)

is evidence for an Akt-eNOS-MMP9-sKitL pathway that could be involved in release of EPCs into the circulation [20]. The most important explanation for these conflicting results is the heterogeneity in our population. The variation, shown in Fig. 4c, within and among patients is too large to draw firm conclusions; in general, there is no clear effect of the treatment, other than a slight decrease rather than the expected increase of CAC numbers following UAG treatment. An important difference between the studies was that the T2D subjects described in the paper of Togliatto et al. had not been medicated [20]. They were treated with diet alone. In contrast, four of our eight patients were on statins and two used antihypertensive medication. Davignon et al. [32] showed that statins generate potent anti-inflammatory actions and can also improve dysfunctional EPC populations in vitro [33-36]. A potential molecular mechanism of statin action on EPC might involve the PI3 K/Akt pathway [34] and the inhibition of apoptosis [37]. In our population four patients received statin treatment (patient $1,4,5$ and 8 ). The statin treatment was put on hold 1 day before testing. With their long half- life, especially of atorvastatin, we can still expect a carry-over effect during the UAG administration in our study. However, a sub-analysis of the statinusing group showed no significant differences between this group and the subjects that did not use statins. This may be caused by the large inter- and intra-individual differences and the small group size. Other studies show that the angiotensin-converting enzyme (ACE) inhibitors such as ramipril [38] and angiotensin II (AT II) inhibitors, like valsartan [39] can increase EPC levels in 
patients, probably interfering with the CD26/dipeptidyl peptidase IV system. One patient used ramipril, but this treatment was not associated with an increase in the number of circulating CAC. Furthermore, all patients were being treated with metformin, that was stopped 1 day prior to the start of each treatment period. Chronic treatment with metformin in obese patients with T2D did not change ghrelin levels before and after start with metformin [40]. Ida et al., showed in 12 RCTs that there were no significant differences in ghrelin levels [41]. The effect of metformin on UAG is unknown. If there is an effect on UAG, it was similarly in all the patients because metformin was stopped at the same time in all patients. Another explanation for our inconclusive results is the notion that our population with a mean HbAlc of $49 \mathrm{mmol} / \mathrm{mol}(6.6 \%)$ was well regulated. Loomans et al. [30] observed a significant inverse correlation between the number of circulating EPC and HbAlc levels in patients with type 1 diabetes. On average, this population had a $40 \%$ reduction in the circulating number of short term cultured EPC, and an HbA1c of more than $8 \%$ [30]. These EPC were cultured as described by Murohara [26], described in our study as Toyo-CAC. The question remains whether the number of $C A C$ are affected in our mild diabetics. Loomans et al. obtained similar results in a hyperglycemic mouse model [30]. In this study, it was found that HMG-CoA (3-hydroxy-3-methylglutaryl coenzyme A) reductase inhibitors overcome the effects of hyperglycemia on EPC. Adding this Atorvastatin in vitro to bone marrow differentiation cultures increased the number of EPC and conversely decreased the number of macrophages. Interestingly, this study showed that statin treatment directly increases myeloid EPC generation in vitro from $\mathrm{BM}$ precursors derived from mice rendered diabetic by streptozotocin treatment.

In all human samples placebo treatment decreased the yields in macrophage cultures. Maybe this is due to the change of environment. For example the stress of a hospital visit may have caused lower numbers of macrophages. Pre-treatment samples were taken within $1 \mathrm{~h}$ after admission and it is known that stress and physical activity increase numbers of circulating leukocytes, including monocytes [27, 42]. Furthermore, the numbers of circulating cells, including monocytes and different populations of EPC, are known to be influenced by circadian variation $[43,44]$. Since pre- and post-treatment collection of peripheral blood differ only by $3 \mathrm{~h}$ (i.e. 16:00 vs. 13:00 h), it is unlikely that this difference plays a significant role in the observed variability.

An explanation for the high degree of variation observed in the CAC and macrophage cultures can only be speculative at this point. Technical variation may add to the diversity, although we have reason to believe that this contribution is limited. As indicated above, we obtained a very consistent yield of CAC and/or macrophages in a number of pre-treatment samples from individual patients, and these values were acquired in cultures generated over several weeks and at different time points during the study. That leaves a potentially significant contribution of inter- and intra-individual differences induced by inborn as well as environmental conditions as the most likely reason for the observed variability in CAC and macrophage generation.

We have previously reported that a short-term high fat diet causes a doubling in abdominal white fat mass in mice, and significantly impairs insulin sensitivity and glucose tolerance [11]. Using this model we showed that long-term (4 week) UAG infusion at $10 \mu \mathrm{g} / \mathrm{kg} / \mathrm{h}$ blocked these effects. Utilizing mice from this study we here also assess the ability of bone marrow progenitors to differentiate into CAC in either vehicle or UAG infused lean or obese mice. Like Togliatto et al. we found that UAG caused an increase in recovery of CAC from differentiated bone marrow cell cultures in obese mice [20]. However, we also find a similar effect in lean mice. In either diet condition, we observed no changes in the generation of macrophages from bone marrow precursors upon treatment with UAG, as reported in our previous study [11]. These data might suggest that longer term treatment in humans may be necessary to observe consistent effects of UAG treatment on CAC, however additional studies are necessary, to confirm this.

\section{Abbreviations}

ACE: angiotensin-converting enzyme; AG: acylated ghrelin; ATIl: angiotensinll; BMI: body mass index; CAC: circulating angiogenic cells; EPC: endothelial progenitor cells; GH: growth hormone; GHSR1a: growth hormone secretagogue receptor; GOAT: ghrelin O-acyl transferase; HbA1c: glycosylated hemoglobin levels; HFD: high fat diet; HMG-CoA: 3-hydroxy-3-methylglutaryl coenzyme A; ND: normal diet; PBMC: peripheral blood mononuclear cells; PFA: paraformaldehyde; SBM: standard breakfast meal; UAG: unacylated ghrelin.

\section{Authors' contributions}

$\mathrm{BO}$ contributes to the design and the conduct of the study, interpretation of data and the writing process of the paper. PL, SN, AJL: participated in the writing of the manuscript. LB and PD analysis of the data and revision of the manuscript. All authors read and approved the final manuscript.

\section{Author details \\ ${ }^{1}$ Department of Internal Medicine, Erasmus MC, Rotterdam, The Netherlands. 2 Department of Immunology, Erasmus MC, Rotterdam, The Netherlands.}

\section{Acknowledgements}

The authors want to thank S. Poldermans, E. van Eck, T. Iqbal, S. Michels and A. van Oudenaren for their splendid logistical and technical support.

\section{Competing interests}

A J van der Lely is a scientific advisor, shareholder of Alize' Pharma. The other authors declare that they have no competing interests. 


\section{Availability of data and materials}

The datasets generated during and/or analysed during the current study are available from the authors upon reasonable request.

\section{Declarations}

The study was conducted in Erasmus University Medical Center Rotterdam after approval by the local IRB.

Animal experiments were performed with the approval of the Animal Ethics Committee at Erasmus MC (approval code: EMC2050).

\section{Publisher's Note}

Springer Nature remains neutral with regard to jurisdictional claims in published maps and institutional affiliations.

\section{Received: 17 October 2016 Accepted: 17 May 2017}

Published online: 31 May 2017

\section{References}

1. Hosoda H, Kojima M, Kangawa K. Biological, physiological, and pharmacological aspects of ghrelin. J Pharmacol Sci. 2006;100:398-410.

2. Broglio F, Gottero C, Prodam F, Gauna C, Muccioli G, Papotti M, et al. Non-acylated ghrelin counteracts the metabolic but not the neuroendocrine response to acylated ghrelin in humans. J Clin Endocrinol Metab. 2004;89:3062-5.

3. Muller TD, Nogueiras R, Andermann ML, Andrews ZB, Anker SD, Argente J, et al. Ghrelin. Mol Metab. 2015;4:437-60.

4. Kojima M, Hosoda H, Date Y, Nakazato M, Matsuo H, Kangawa K. Ghrelin is a growth-hormone-releasing acylated peptide from stomach. Nature. 1999;402:656-60

5. Kojima M, Kangawa K. Ghrelin: more than endogenous growth hormone secretagogue. Ann NY Acad Sci. 2010;1200:140-8.

6. Gauna $C$, van de Zande B, van Kerkwijk A, Themmen AP, van der Lely AJ, Delhanty PJ. Unacylated ghrelin is not a functional antagonist but a full agonist of the type 1a growth hormone secretagogue receptor (GHS-R). Mol Cell Endocrinol. 2007:274:30-4.

7. Broglio F, Benso A, Gottero C, Prodam F, Gauna C, Filtri L, et al. Nonacylated ghrelin does not possess the pituitaric and pancreatic endocrine activity of acylated ghrelin in humans. J Endocrinol Invest. 2003;26:192-6.

8. Gauna C, Meyler FM, Janssen J, Delhanty PJD, Abribat T, Van Koetsveld $P$, et al. Administration of acylated ghrelin reduces insulin sensitivity whereas the combination of acylated plus unacylated ghrelin strongly improves insulin sensitivity. J Clin Endocrinol Metab. 2004;89:5035-42.

9. Ozcan B, Neggers SJ, Miller AR, Yang HC, Lucaites V, Abribat T, et al. Does des-acyl ghrelin improve glycemic control in obese diabetic subjects by decreasing acylated ghrelin levels? Eur J Endocrinol. 2014;170:799-807.

10. Delhanty PJ, Sun Y, Visser JA, van Kerkwijk A, Huisman M, van ljcken WF, et al. Unacylated ghrelin rapidly modulates lipogenic and insulin signaling pathway gene expression in metabolically active tissues of GHSR deleted mice. PLoS ONE. 2010;5:e11749.

11. Delhanty PJ, Huisman M, Baldeon-Rojas LY, van den Berge I, Grefhorst A, Abribat T, et al. Des-acyl ghrelin analogs prevent high-fat-diet-induced dysregulation of glucose homeostasis. FASEB J. 2013;27:1690-700.

12. Fonseca V, Desouza C, Asnani S, Jialal I. Nontraditional risk factors for cardiovascular disease in diabetes. Endocr Rev. 2004:25:153-75.

13. Beckman JA, Creager MA, Libby P. Diabetes and atherosclerosis: epidemiology, pathophysiology, and management. JAMA. 2002:287:2570-81.

14. Kanter JE, Bornfeldt KE. Inflammation and diabetes-accelerated atherosclerosis: myeloid cell mediators. Trends Endocrinol Metab. 2013:24:137-44

15. Prater DN, Case J, Ingram DA, Yoder MC. Working hypothesis to redefine endothelial progenitor cells. Leukemia. 2007:21:1141-9.

16. Timmermans F, Plum J, Yoder MC, Ingram DA, Vandekerckhove B, Case J. Endothelial progenitor cells: identity defined? J Cell Mol Med. 2009;13:87-102

17. Tepper OM, Galiano RD, Capla JM, Kalka C, Gagne PJ, Jacobowitz GR, et al. Human endothelial progenitor cells from type II diabetics exhibit impaired proliferation, adhesion, and incorporation into vascular structures. Circulation. 2002;106:2781-6.

18. Thum T, Fraccarollo D, Schultheiss M, Froese S, Galuppo P, Widder JD, et al Endothelial nitric oxide synthase uncoupling impairs endothelial progenitor cell mobilization and function in diabetes. Diabetes. 2007:56:666-74.

19. Urbich C, Dernbach E, Rossig L, Zeiher AM, Dimmeler S. High glucose reduces cathepsin $L$ activity and impairs invasion of circulating progenitor cells. J Mol Cell Cardiol. 2008;45:429-36.

20. Togliatto G, Trombetta A, Dentelli P, Baragli A, Rosso A, Granata R, et al. Unacylated ghrelin rescues endothelial progenitor cell function in individuals with type 2 diabetes. Diabetes. 2010;59:1016-25.

21. Benso A, St-Pierre DH, Prodam F, Gramaglia E, Granata R, van der Lely AJ, et al. Metabolic effects of overnight continuous infusion of unacylated ghrelin in humans. Eur J Endocrinol. 2012;166:911-6.

22. Allen NA, Fain JA, Braun B, Chipkin SR. Continuous glucose monitoring in non-insulin-using individuals with type 2 diabetes: acceptability, feasibility, and teaching opportunities. Diabetes Technol Ther. 2009;11:151-8.

23. Maia FF, Araujo LR. Efficacy of continuous glucose monitoring system (CGMS) to detect postprandial hyperglycemia and unrecognized hypoglycemia in type 1 diabetic patients. Diabetes Res Clin Pract. 2007;75:30-4

24. Murphy HR, Rayman G, Lewis K, Kelly S, Johal B, Duffield K, et al. Effectiveness of continuous glucose monitoring in pregnant women with diabetes: randomised clinical trial. BMJ (Clinical research ed). 2008;337:a1680.

25. Tanenberg R, Bode B, Lane W, Levetan C, Mestman J, Harmel AP, et al. Use of the continuous glucose monitoring system to guide therapy in patients with insulin-treated diabetes: a randomized controlled trial. Mayo Clin proc. 2004;79:1521-6.

26. Murohara T, Ikeda H, Duan J, Shintani S, Sasaki K, Eguchi H, et al. Transplanted cord blood-derived endothelial precursor cells augment postnatal neovascularization. J Clin Invest. 2000;105:1527-36.

27. Asahara T, Takahashi T, Masuda H, Kalka C, Chen D, Iwaguro H, et al. VEGF contributes to postnatal neovascularization by mobilizing bone marrowderived endothelial progenitor cells. EMBO J. 1999;18:3964-72.

28. Sklar MD, Tereba A, Chen BD, Walker WS. Transformation of mouse bone marrow cells by transfection with a human oncogene related to c-myc is associated with the endogenous production of macrophage colony stimulating factor 1. J Cell Physiol. 1985;125:403-12.

29. Wrobel K, Claudio E, Segade F, Ramos S, Lazo PS. Measurement of cytotoxicity by propidium iodide staining of target cell DNA. Application to the quantification of murine TNF-alpha. J Immunol Methods. 1996;189:243-9.

30. Loomans CJ, van Haperen R, Duijs JM, Verseyden C, de Crom R, Leenen PJ, et al. Differentiation of bone marrow-derived endothelial progenitor cells is shifted into a proinflammatory phenotype by hyperglycemia. Mol Med. 2009:15:152-9.

31. Waltenberger J. Impaired collateral vessel development in diabetes: potential cellular mechanisms and therapeutic implications. Cardiovasc Res. 2001:49:554-60.

32. Davignon J. Beneficial cardiovascular pleiotropic effects of statins. Circulation. 2004:109:11139-43.

33. Llevadot J, Murasawa S, Kureishi Y, Uchida S, Masuda H, Kawamoto A, et al. HMG-CoA reductase inhibitor mobilizes bone marrow-derived endothelial progenitor cells. J Clin Invest. 2001;108:399-405.

34. Dimmeler S, Aicher A, Vasa M, Mildner-Rihm C, Adler K, Tiemann M, et al. HMG-CoA reductase inhibitors (statins) increase endothelial progenitor cells via the PI 3-kinase/Akt pathway. J Clin Invest. 2001:108:391-7.

35. Walter DH, Rittig K, Bahlmann FH, Kirchmair R, Silver M, Murayama T, et al. Statin therapy accelerates reendothelialization: a novel effect involving mobilization and incorporation of bone marrow-derived endothelial progenitor cells. Circulation. 2002;105:3017-24.

36. Gazzerro P, Proto MC, Gangemi G, Malfitano AM, Ciaglia E, Pisanti S, et al. Pharmacological actions of statins: a critical appraisal in the management of cancer. Pharmacol Rev. 2012;64:102-46.

37. Urbich C, Knau A, Fichtlscherer S, Walter DH, Bruhl T, Potente M, et al. FOXO-dependent expression of the proapoptotic protein Bim: pivotal role for apoptosis signaling in endothelial progenitor cells. FASEB J. 2005;19:974-6.

38. Ariyasu H, Takaya K, Iwakura H, Hosoda H, Akamizu T, Arai Y, et al. Transgenic mice overexpressing des-acyl ghrelin show small phenotype. Endocrinology. 2005;146:355-64. 
39. Bahlmann FH, de Groot K, Mueller O, Hertel B, Haller H, Fliser D. Stimulation of endothelial progenitor cells: a new putative therapeutic effect of angiotensin II receptor antagonists. Hypertension. 2005;45:526-9.

40. Thondam SK, Cross A, Cuthbertson DJ, Wilding JP, Daousi C. Effects of chronic treatment with metformin on dipeptidyl peptidase-4 activity, glucagon-like peptide 1 and ghrelin in obese patients with type 2 diabetes mellitus. Diabet med J Br Diabet Assoc. 2012;29:e205-10.

41. Ida S, Murata K, Kaneko R. Effects of metformin treatment on blood leptin and ghrelin levels in patients with type 2 diabetes mellitus. J Diabetes. 2017;9(5):526-35.
42. Ho CS, Lopez JA, Vuckovic S, Pyke CM, Hockey RL, Hart DN. Surgical and physical stress increases circulating blood dendritic cell counts independently of monocyte counts. Blood. 2001;98:140-5.

43. Born J, Lange T, Hansen K, Molle M, Fehm HL. Effects of sleep and circadian rhythm on human circulating immune cells. J Immunol. 1997; 158:4454-64.

44. Thomas HE, Redgrave R, Cunnington MS, Avery P, Keavney BD, Arthur HM Circulating endothelial progenitor cells exhibit diurnal variation. Arterioscler Thromb Vasc Biol. 2008;28:e21-2.

\section{Submit your next manuscript to BioMed Central and we will help you at every step:}

- We accept pre-submission inquiries

- Our selector tool helps you to find the most relevant journal

- We provide round the clock customer support

- Convenient online submission

- Thorough peer review

- Inclusion in PubMed and all major indexing services

- Maximum visibility for your research

Submit your manuscript at www.biomedcentral.com/submit 